\title{
Sclerotheraphy of Superficial Intraoral Hemangioma: A Case Report with Reviews
}

\section{ARUNA NGANGOM ${ }^{1}$, MAYANK JAIN²}

Hemangiomas are common benign neoplasm due to proliferation of blood vessels. The treatment modalities of Hemangioma are varied from Intralesional and systemic corticosteroid treatment to surgical excision, thermocauterization, laser photocoagulation and sclerotherapy. However, each treatment has its own risks and benefits. Use of sclerosing solution is the most convenient, effective and inexpensive treatment modalities especially in oral and peri-oral hemangioma lesions. Here presenting a case report of right upper lip Hemangioma successfully treated with multiple local injections of $3 \%$ sodium tetradecyl solution with their prognosis.

KEYWORDS: Sclerotherapy, Hemangioma, Intraoral, Superficial

\section{INTRODUCTION}

Hemangiomas are common benign neoplasms due to proliferation of blood vessels. They can appear on any site of the body. Orally and peri-orally, they are commonly seen on upper lips which can cause esthetic and functional problems to patients. They can also appear on other sites of the oral cavity like buccal mucosa, tongue and palate. Its definitive diagnosis is obtained by different methods of clinical examination and investigations like digital compression and diascopy and other supplementary imaging tests such as ultrasonography and MRI.

Various treatment modalities like surgical excision, laser therapy, cauterization, cryotherapy, radiotheraphy, silver nitrate and sclerosing solution have been used depending on size, site, depth and involvement of adjacent structure(s).

The use of sclerosing solution is the most convenient, effective and inexpensive treatment modalities especially in oral and peri-oral hemangioma lesions. We hereby present a case report of a right upper lip hemangioma successfully treated with multiple local injections of $3 \%$ sodium tetradecyl solution.

\section{CASE REPORT}

A 16 year old female patient reported to the department of Oral Medicine and Radiology with chief complaint of esthetic problems due to blue colored swelling of upper left lip. The patient reported that she had noticed the lesion more than 4 years ago and was asymptomatic. She also gave a positive history of the habit of biting her lip and noticed that the size of the swelling increases while crying.

Extra-oral examination revealed facial asymmetry that was evident due to swelling on the left upper lip (Figure. 1). Intraoral examination revealed a welldefined, purpled colored lesion of $12 \times 10 \mathrm{~mm}$ in size approximately. The overlying mucosa was intact with smooth overlying skin. On palpation, the lesion was soft in consistency, non-tender, blanched on digital pressure with normal overlying temperature (Figure. 2)

From the history and clinical examination, a provisional diagnosis of Hemangioma was formulated with differential diagnosis of Arteriovenous malformation and Lymphangioma. The patient was advised for ultrasound spectral doppler flow of upper lip with high-frequency probe in which an echographic abnormality in subcutaneous tissue of the left upper lip was observed. Doppler imaging revealed that the tissue observed was hypoechoic, which was discretely heterogenous with a regular outline with low resistance flow of vessels, confirming the diagnosis of Hemangioma. The patient was further subjected to sclerotherapy with $0.05 \mathrm{~g} / \mathrm{ml}$ of sodium tetradecyl solution.

\section{CASE DISCUSSION}

A 16-year-old female patient reported in the department of Oral Medicine and Radiology of our institution with chief complaint of swelling of left upper lip. The swelling was observed 4 to 5 years back which gradually increased to size of $10 \times 12 \mathrm{~mm}$ 
and patient's main concern was an unesthetic appearance of the swelling. The swelling was gradual in onset and aggravated upon the presence of any stressful condition or while crying. The general health condition of the patient was normal with no underlying systemic problems. The swelling was bluish in color with the overlying skin lobulated, dry and with well- defined margins. Palpation revealed that the swelling was firm, non-tender and rubbery in texture with blanching present upon application of pressure. A provisional diagnosis of haemangioma was formulated with the differential diagnosis of arteriovenous malformation and lymphangioma.

The patient was advised ultrasound spectral doppler flow with routine blood examination. Except for a low haemoglobin count $(10.2 \%)$, other blood workup values were in normal limits. An ultrasound spectral doppler flow of upper lip with high-frequency probe showed a small hypoechoic mass which appeared to be superficial to the muscle on the upper left sided region of lip. An increased arterial/venous flow in the swelling mass with normal underlying structure were also evident. Thus, ultrasound spectral doppler flow suggested vascular malformation of upper left lip. The patient was treated with intralesional injection of sclerosing agent $30 \mathrm{mg} / \mathrm{ml}$ of SETROL, sodium tetradecyl sulfate (STS).

Procedure: After applying topical anesthetic spray (15\% xylocaine spray) over the lesion, using a small insulin syringe, approximately $1-1.05 \mathrm{ml}$ of $3 \%$ STS were injected at multiple sites. The intralesional injection was administered first at periphery then on the centre of the lesion followed by manual compression. The injection was repeated after every 10 days. A total of 3 injections were given. The size of the lesion was considerably decreased with an esthetic improvement in every visit (Figure. 3\&4). Analgesic and anti-inflammatory medications was given to patient to control the slight pain and mild local inflammatory reaction observed in the injections sites.

At 9-month follow-up visit (Figure. 5), a satisfactory esthetic result with a significant reduction in size of the lesion as compared to the first visit was observed.

\section{DISCUSSION}

The treatment modalities of hemangioma vary depending on the location, size and nature of lesion, whether arterial or venous. Intra-lesional and systemic corticosteroid treatment, surgical excision, thermocauterization, laser photocoagulation and sclerotherapy are some of the treatments routinely done for hemangioma. ${ }^{1}$ However, each treatment has its own risks and benefits.

Among all these treatments, sclerotherapy is more non-invasive, inexpensive and readily available with minimal side-effects., ${ }^{1,2}$ It has also shown better efficacy with partial or complete regression without bleeding as compared to other treatment modalities. ${ }^{3-7}$ Commonly used sclerosing solutions are sodium morrhuate, sodium psylliate, hypertonic glucose solution, sodium tetradecyl sulphate and ethanolamine oleate. ${ }^{8-10}$

Certain precautions and guidelines have to be followed in sclerotherapy, although it is a simple technique. It should be administered using an insulin needle and directly injected at the centre of lesions, thereby reducing the chances of necrosis of the surrounding tisues. ${ }^{8,9,11}$ The injection solution usually should not exceed $2 \mathrm{~mL}$, although the quantity may depend on the size of lesions. Multiple injections are required to achieve the desired results and are administered with an interval of 1 to 2 weeks. ${ }^{8,9,12}$

However, sclerotherapy has its own side-effects like anaphylactic reactions to sensitive patients, local tissue necrosis etc. It is commonly avoided in pregnant or expectant mothers for its teratogenic effects , uncontrolled diabetic patients. ${ }^{11}$

\section{CONCLUSION}

Sclerotherapy is a very effective, non-invasive, inexpensive method with a better esthetic result for intraoral hemangioma. Thus, it can be considered as the preferred treatment option for all superficial hemangiomas.

\section{REFERENCES}

1. Minkow B, Laufer D, Gutman D. Treatment of oral hemangiomas with local sclerosing agents. International Journal of Oral Surgery 1979;8(1):18-21. 2. Selim H, Selim A, Khachemoune A, Metwally SAFA. Use of sclerosing agent in the management of oral and perioral hemangiomas: review and case reports. Medical Science Monitor 2007;13(9):CS114-CS119.

3. Rodrigues Johann ACB, Ferreira Aguiar MC, Vieira Do Carmo MA, Gomez RS, Castro WH, Mesquita RA. Sclerotherapy of benign oral vascular lesion with ethanolamine oleate: an open clinical trial with 30 
lesions. Oral surgery, Oral Medicine, Oral Pathology, Oral Radiology and Endodontology 2005; $100(5): 579-84$

4. H. Winter, E. Dräger, and W. Sterry, "Sclerotherapy for treatment of hemangiomas," Dermatologic Surgery 2000; 26(2):105-8.

5. Hou J, Wang M, Tang H, Wang Y, Huang $H$. Pingyangmycin sclerotherapy for infantile hemangiomas in oral and maxillofacial regions: an evaluation of 66 consecutive patients. Int J Oral Maxillofac Surg. 2011;40(11):1246-51.

6. Zheng JW, Zhang ZY et al. Treatment Guideline For Hemangiomas And Vascular Malformations Of The Head And Neck: Head \& Neck 2010; 1088-98.

7. Mulliken JB, Glowacki J. Hemangiomas and vascular malformations in infants and children: a classification based on endothelial characteristics. Plast Reconstr Surg. 1982;69(3):412-22.

8. Abdyli RA, Abdyli Yll, Perjuci F, Gashi A, Agani Z, Ahmedi J. Sclerotherapy of Intraoral Superficial Hemangioma. Case Reports in Dentistry;2016: 4320102.

9. Saraf S. Role of sodium tetradecyl sulfate in venous malformations. Indian J Dermatol 2006;51:258-61.

10. M K P, Koppal S, Rukmangada T, et al. BMJ Case Rep 2013: Article ID: 200660
11. Johann AC, Aguiar MC, do Carmo MA, Gomez RS, Castro WH, Mesquita RA. Sclerotherapy of benign oral vascular lesion with ethanolamine oleate: an open clinical trial with 30 lesions. Oral Surg Oral Med Oral Pathol Oral Radiol Endod. 2005;100(5):579-84. 12. Agarwal S. Treatment of Oral Hemangioma with 3\% Sodium Tetradecyl Sulfate: Study of 20 Cases Indian J Otolaryngol Head Neck Surg 2012;64(3):2057 .
Source of support: Nil, Conflict of interest: None declared
Cite this article as:

Ngangom A, Jain M. Sclerotheraphy of Superficial Intraoral Hemangioma: A Case Report with Reviews. Int Healthcare Res J 2018;2(3):59-62. doi: 10.26440/IHRJ/02_03/173

\section{AUTHOR AFFILIATIONS:}

1. Professor and HOD

2. Assistant Professor

Department of Oral Medicine and Radiology, D.A.V. (C) Dental College, Yamunanagar:

\section{Corresponding Author:}

Dr. Aruna Ngangom

Professor and HOD

Department of Oral Medicine and Radiology)

D.A.V. (C) Dental College, Yamunanagar.
For article enquiry/author contact details, e-mail at: manuscriptenquiry.ihrj@gmail.com 


\section{LEGENDS}

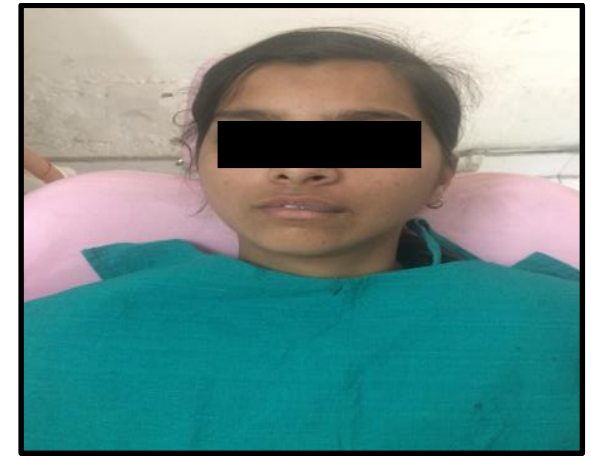

Figure 1. $1^{\text {st }}$ Visit: Facial asymmetry that was evident due to swelling on the left upper lip

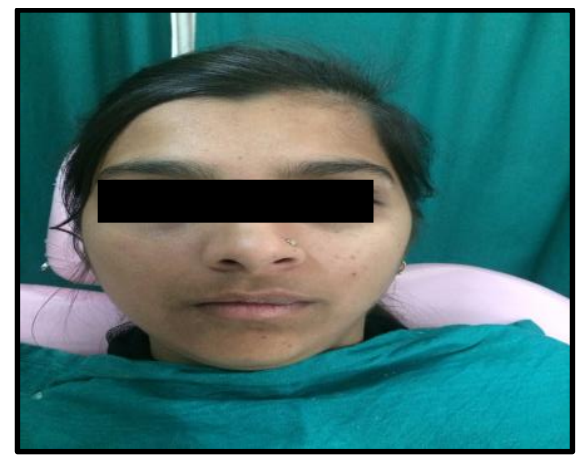

Figure $3 \cdot 2^{\text {nd }}$ Visit; Extra-oral view

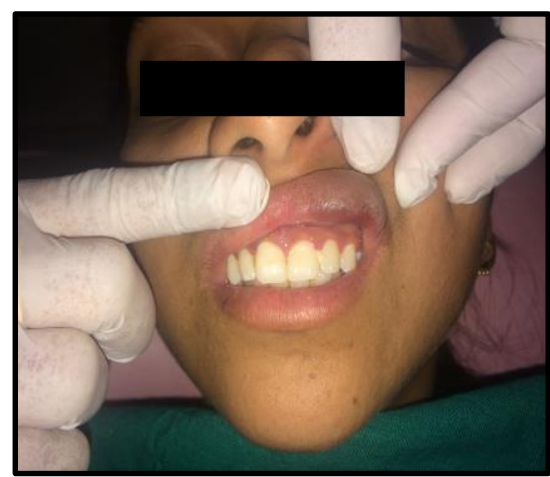

Figure 2: $1^{\text {st }}$ Visit, Extraoral view; On palpation, the lesion was soft in consistency, non-tender, blanched on digital pressure with normal overlying temperature

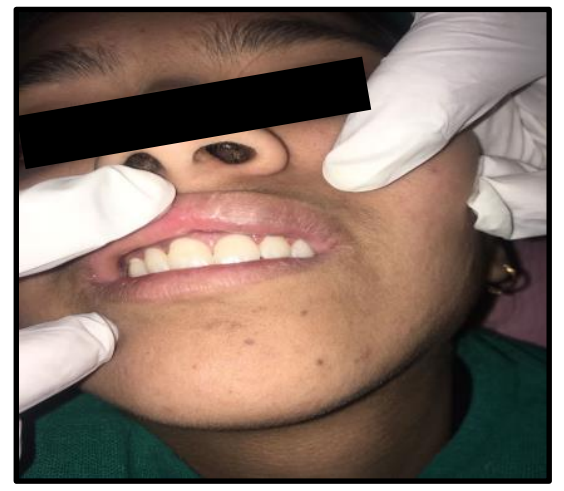

Figure $4 \cdot 2^{\text {nd }}$ Visit: Intraoral View: improvement in aesthetic appearance

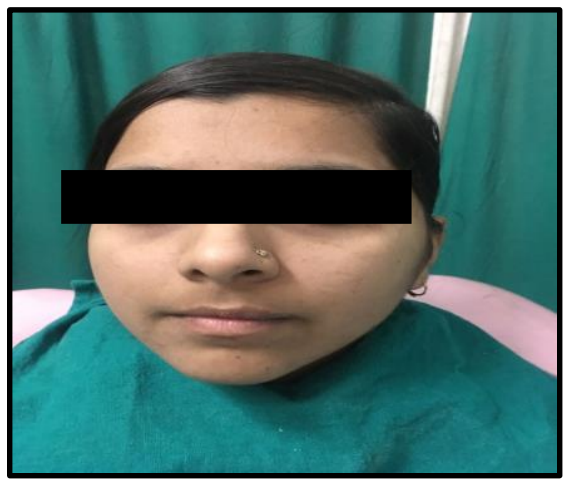

Figure 5. $9^{\text {th }}$ Visit; Resolution of the lesion 